\title{
The Incidence and Character of Vibrios in British Waters
}

\author{
By ROSEMARY JACKSON \\ National Institute for Medical Research, Hampstead, London
}

SUMMARY : Forty-nine strains of vibrio were isolated from 32 of 43 samples of fresh water collected in various parts of England and Wales during the period October 1945 to July 1946. More than one kind of vibrio were found in 14 of the samples.

The types of vibrio isolated were heterogeneous in their fermentation reactions. Only three gave a cholera-red reaction. Twenty-five produced haemolysin for goat erythrocytes and all the haemolysins tested were filterable through gradacol membranes of $75 \mathrm{~m} \mu$ pore diameter; an antiserum prepared against the haemolysin of one strain neutralized those of the other haemolytic water strains and of an El Tor vibrio.

Only one serological group of five strains related in ' $O$ ' and ' $H$ ' antigens was found; a few other strains showed $H$ relationship and one (or two) possessed the $\mathrm{H}$ antigen of Vibrio cholerae; otherwise the organisms isolated were serologically heterogeneous with little antigenic similarity to one another or to known Asiatic vibrio types.

Compared with the extensive studies of the organisms of the Vibrio group which have been undertaken in India and the Far East, there is little information concerning their distribution and characters in western countries where cholera no longer occurs. In Britain, Houston (1913) examined a large number of London water samples, mainly from the Thames, for the presence of 'water microbes culturally resembling vibrios', but after finding 1885 strains atypical in the cholera-red test and in their behaviour towards gelatin he rejected them without further study.

The present investigation was therefore started with the following objects: (1) to determine the incidence of vibrios in open waters in this country; (2) to investigate their biochemical and serological characters; (3) to compare them with the true cholera vibrio and with water vibrios isolated in other parts of the world.

\section{Method of isolation}

Specimens were taken in ordinary unsterilized glass beakers, washed out several times in the water under examination. Each sample $(180 \mathrm{ml}$.) was transferred to a sterile screw-capped bottle containing $20 \mathrm{ml}$. of an enrichment medium composed of $10 \%$ peptone and $9 \% \mathrm{NaCl}$ in distilled water, with the pH adjusted to $9 \cdot 2$ and buffered with a boric acid solution, a few drops of thymol blue being added as indicator. The samples were usually collected during the afternoon and on returning to the laboratory the bottles were left on the bench at room temperature overnight. They were transferred to the $37^{\circ}$ incubator at 10 a.m. the following day for $6 \mathrm{hr}$., after which a few drops of the surface scum was plated on Aronson agar. The bottles were again left on the bench overnight and a second plating was made the following morning. 


\section{Incidence of vibrios in water}

During the period October 1945 to July 1946, 43 water samples from various parts of England and Wales were examined and vibrios were isolated from 32 of them. From 14 of the samples more than one type of vibrio was obtained (Table 1).

Although the media used were basically similar to those used in India by Taylor \& Ahuja (1937), and found by them highly selective in their investigation of waters in Northern India, considerable difficulty was experienced in suppressing other water bacteria which tended to overgrow the more delicate vibrio. The procedure of isolation was adjusted from time to time. It was found that vibrios could often be picked up off plates, negative at first examination, which had been lying on the bench for several days, and it became the practice to examine all plates daily for a week before rejecting them as negative. This method was eventually adopted as giving the greatest number of positive results. It is probable that earlier failures to isolate vibrios from some of the samples were due to inadequacies of technique and that the incidence is actually higher than the $75 \%$ found in this small survey.

At the beginning of the investigation, a period during which results were variable, the weather was mild and damp, but the samples from sources 22 , 23 and 24, which failed to yield vibrios, were collected during a cold spell when there was snow on the ground, although no ice on the surface of the water. From March 1946 onwards all collections were made during warm weather and there were no vibrio-free samples. The series is, however, too small to allow any conclusions to be drawn about the influence of weather on incidence. Other observers (Houston, 1909; Taylor \& Ahuja, 1937) were of the opinion that it did not play any definite part.

It is obvious, however, that organisms of the vibrio group are very widely distributed in the waters of this country and are to be found in such diverse sources as hill streams, rain-water collections and stagnant ponds.

\section{Biochemical characters of the strains isolated}

Fermentation reactions. The fermentation reactions of all the strains with mannose, sucrose and arabinose were studied and the vibrios classified according to the six types of Heiberg (1935). Organisms of type I formed by far the largest group, comprising $64 \%$ of the whole series; $12 \%$ only were of type II, and $16 \%$ of type VI. There were none of types IV and V and only two organisms of type III. The non-fermenting group of type VI was subdivided into two subtypes according to the reactions with mannitol and glucose. Only one, no. $3 b$, fermented these sugars, thus falling into subtype 2 , and the others remained non-fermenters of subtype 1 . The overwhelming predominance of type I, to which Vibrio cholerae belongs, is of interest. Taylor, Read \& Pandit (1936), in a study of the fermentation reactions of recently isolated vibrios from patients with cholera, carriers and water sources in the Calcutta area, found that only $11.4 \%$ of vibrios isolated from waters belonged 
to type I, while $87 \%$ were of type II. In a later study of water vibrios in Northern India, Taylor \& Ahuja (1938) found that during the cold weather strains of type II formed only $6 \%$ and type I $28 \%$. The incidence of type VI

\section{Table 1. Waters investigated for the presence of vibrios}

No. of source

1

2

3

4

5

6

7

8

9

10

11

12

18

14

15

16

17

18

19

20

21

22

23

24

25

26

27

28

29

30

31

32

33

34

35

36

37

38

39

40

41

42

48

\section{Source of water}

Hampstead Heath duck pond (a), London Hampstead Heath swimming pond, London Hampstead Heath duck pond (b), London Leg o' Mutton pond, Hampstead, London Stream, Golders Hill Park, London Pond, Barnet-bypass, Middlesex Pond, Mote Mount Golf Course, Barnet Serpentine lake, Hyde Park, London Round Pond, Kensington Gardens, London River Thames at Westminster Bridge, London Fountain pool, Trafalgar Square, London Horse pond, Putney Heath, London Beverly Brook, Ranelagh Club Pond 1, Barn Elms Park Pond 2, Barn Elms Park

Pond, Convent grounds, Roehampton

River Thames at Hammersmith Bridge, London

Canal, Regent's Park, London

Boating lake, Regent's Park, London

New River, Palmer's Green, London

Mill stream, Bowcombe, S. Devon

Hill spring, Bowcombe, S. Devon

Cattle trough, Bowcombe, S. Devon

Spring, Bowcombe, S. Devon

Rain water from butt, Kingsbridge, Devon

Pond, Kingsbury, Middlesex

Swift stream, slate quarry, N. Wales

Stream, Gate of Clwyd, N. Wales

Drinking trough, Llanbedr, N. Wales

North Lake, Kew Gardens, London

Stream, Rock Garden, Kew, London

South Lake, Kew Gardens, London

Lily pond in hot-house, Kew, London

River Thames at Kew, London

Roadside stream, Totland, Isle of Wight

Ditch, Freshwater, Isle of Wight

Duck pond, Compton, Isle of Wight

River Thames at Tower Bridge, London

River Thames at Greenwich, London

Stream, Worcester Park, Surrey

River Thames at Richmond, London

River Thames at Hampton Court, Surrey
Horse pond, Yarmouth, Isle of Wight

\begin{tabular}{|c|c|}
\hline $\begin{array}{l}\text { Date of } \\
\text { sampling }\end{array}$ & $\begin{array}{l}\text { Vibrio strains } \\
\text { isolated }\end{array}$ \\
\hline $10 \times \cdot 45$ & $\mathbf{1}$ \\
\hline 10. X. 45 & 2 \\
\hline 10. $\times .45$ & $3 a, 3 b$ \\
\hline 16. X. 45 & - \\
\hline 16. $x .45$ & - \\
\hline $17 . \times .45$ & - \\
\hline $17 . \times 45$ & - \\
\hline 23. x. 45 & $4 a, 4 b$ \\
\hline 23. x. 45 & $5 a, 5 b$ \\
\hline 28. x. 45 & $6 a, 6 b$ \\
\hline 23. $x \cdot 45$ & $\ldots$ \\
\hline 30. X. 45 & — \\
\hline 30. X. 45 & 7 \\
\hline 30. x. 45 & - \\
\hline 80. X. 45 & 8 \\
\hline 30. x. 45 & - \\
\hline 30. x. 45 & 9 \\
\hline 5. xi. 45 & 10 \\
\hline 5. xi. 45 & - \\
\hline 20. xi. 45 & $11 a, 11 b$ \\
\hline 9. xii. 45 & 12 \\
\hline 9. xii. 45 & - \\
\hline 9. xii. 45 & 一 \\
\hline 9. xii. 45 & - \\
\hline $\begin{array}{l}\text { 21. i. } 46 \\
\text { 8. ii. } 46\end{array}$ & $\begin{array}{c}13 a, 13 b, 13 c, 18 d \\
14 a, 14 b\end{array}$ \\
\hline 24. iii. 46 & $15,15 b, 15 c$ \\
\hline 24. iii. 46 & 22 \\
\hline 24. iii. 46 & 16 \\
\hline 29. iii. 46 & 17 \\
\hline 29. iii. 46 & 18 \\
\hline 29. iii. 46 & $19 a, 19 b$ \\
\hline 29. iii. 46 & $20 a, 20 b$ \\
\hline 29. iii. 46 & $21 a, 21 b$ \\
\hline 23. iv. 46 & 23 \\
\hline 23. iv. 46 & 24 \\
\hline 23. iv. 46 & $25 a, 25 b$ \\
\hline 23. iv. 46 & 26 \\
\hline 22. v. $46^{\circ}$ & $27 a, 27 b$ \\
\hline 22. v. 46 & 28 \\
\hline 25. v. 46 & 29 \\
\hline 11. vii. 46 & $30 a, 30 b$ \\
\hline 11. vii. 46 & $31 a, 31 b$ \\
\hline
\end{tabular}

was also greater, forming another $28 \%$ of the total, as against none in the Calcutta series and $13 \%$ in Northern Indian waters examined during the hot weather and monsoon periods. In the present series six out of the eight type VI vibrio strains were isolated during the coldest part of the year, between the end of November and the beginning of February. 
Cholera-red (C.R.) and indole reactions. The cholera-red reaction was carried out on 24 and $48 \mathrm{hr}$. cultures, in the nitrate peptone broth recommended by Bleisch (1898). In the whole series there were only three positive reactions, and all of these appeared at $24 \mathrm{hr}$. Two of the reacting strains were of Heiberg type I, and the other of type II. In the Indian series, during the hot weather and monsoon periods the incidence of positives was about $40 \%$, but in the cold-weather series no positive cholera-red reactors. were found among the thirty-two strains examined.

Indole was produced by $32 \%$ of the strains, including the three positive in the C.R. test.

Voges-Proskauer (V.P.) test. Barritt's (1936) modification was used as being more sensitive than the ordinary test, and the incidence of positives was $50 \%$. C.R. + strains also reacted positively in the V.P. test, and no Heiberg type I strain was C.R. + V.P. - , a biochemical combination which is considered by Taylor, Pandit \& Read (1937) to provide a presumptive diagnosis of the serological $\mathbf{O}$ group I. On the other hand, the close parallelism found by these authors between the C.R. and V.P. tests has not been borne out in this series. Similar reactions were obtained with 27 of the vibrios and dissimilar reactions with 23 and, unlike the inagglutinable vibrios examined by them, a number of the C.R. - V.P. - group are of Heiberg type I.

Other biochemical tests. All strains were tested for their ability to liquefy gelatin, and to produce hydrogen sulphide. Only $22 \%$ failed to liquefy gelatin, and $21 \%$ of the strains were found to produce hydrogen sulphide after 3 days incubation at $37^{\circ}$.

\section{The haemolysins of the strains isolated}

All strains were tested for haemolysis at 2, 4, 24, 48 and $72 \mathrm{hr}$. The method was similar to that described by Goyle (1939), $1 \mathrm{ml}$. of a $5 \%$ suspension of washed goat cells (packed centrifuged deposit $\mathrm{v} / \mathrm{v}$ ) being added to $1 \mathrm{ml}$. of peptone water culture. After $2 \mathrm{hr}$. at $37^{\circ}$ the tubes were removed to the refrigerator, and the readings taken the following morning.

Approximately $50 \%$ of the strains proved to be haemolytic, and of these all except two gave a positive reading at $24 \mathrm{hr}$. Greig (1914) and Goyle (1939), using Indian and Far Eastern strains, both found maximum haemolysin production in $72 \mathrm{hr}$. cultures, but Goyle also found that some of his weakly haemolytic strains had lost their haemolysin during the 3-day period of incubation, and therefore recommended that tests should be read at successive $24 \mathrm{hr}$. intervals. Taylor et al. (1937), in their study of the cholera-like vibrios, used a $48 \mathrm{hr}$. test as routine. The majority of the haemolytic strains in my series attained their maximum haemolysin production at $24-48 \mathrm{hr}$. and maintained it at $72 \mathrm{hr}$., and none which was haemolytic at $24 \mathrm{hr}$. had lost activity at $72 \mathrm{hr}$. On the other hand, one strain (30a) became haemolytic only at $48 \mathrm{hr}$., and two strains (9 and 10), though quite strongly haemolytic at $4 \mathrm{hr}$., were not haemolytic at $24 \mathrm{hr}$. Two of the strains, $3 b$ and $6 a$, were found to be non-haemolytic when first isolated, but when retested several months later, haemolysed goat cells. This phenomenon has been observed by other authors. 
The haemolysins of two of the strains, selected as being typical members of the series and strongly haemolytic, were further investigated and found to fulfil the criteria required of a true toxin in that they were heat labile, being destroyed by heating at $56^{\circ}$ for $10 \mathrm{~min}$., filterable, and antigenic.

Filterability of the haemolysin. Greig (1914), in his original experiments, filtered haemolytic vibrio cultures through Pasteur-Chamberland candles and, testing the filtrates, found that a considerable diminution had occurred in the process, or in a few cases complete loss of haemolytic activity. He concluded that 'the haemolysin producing substance... is to a considerable extent nonfilterable'. Goyle (1939) used a Pasteur-Chamberland candle, a Seitz E.K. disk and a Berkfeld $\mathrm{N}$ filter, and collected the filtrates in successive $10 \mathrm{ml}$. fractions. He found that the haemolysin was definitely filterable, but tended to be adsorbed on the filter disks or candles. This adsorption was most marked with the Seitz disks and least with the Berkfeld N filter, though even when the latter was used the final filtrate fractions did not attain the haemolytic titres of the unfiltered cultures. In the present investigation supernatant fluid from a centrifuged haemolytic peptone water culture was passed through an Elford gradacol filter membrane of $0.75 \mu$ pore diameter. The filtrate was collected in successive $10 \mathrm{ml}$. fractions and tested for haemolysin in parallel with the unfiltered culture. The first fraction was found to be only weakly haemolytic, with a titre of only $1 / 1$ as against $1 / 512$ of the unfiltered culture, the second produced haemolysis at a dilution of $1 / 32$, and the third was as powerfully haemolytic as the parent culture. The superiority of this type of filter for the purpose was thus demonstrated and Goyle's claim of the filterability of the haemolysin was confirmed.

Antigenicity of the haemolysin. Using Goyle's method, an anti-haemolytic serum was prepared against vibrio $6 b$ and tested against the haemolysins of other vibrios in the series. The anti-haemolytic activity of the serum was not as marked as in Goyle's sera, and a serum concentration of 1/10 was required for complete inhibition of the haemolysin of the vibrio $6 \mathrm{~b}$. Control series were therefore run with all tests, using $1 / 10$ normal serum from the same rabbit. It was found that the serum inhibited the haemolysins of all the British water vibrios and also that of the only El Tor vibrio tested (strain Doorenbos 34D 13).

\section{Serological characters of the strains isolated}

Antisera were prepared against 23 of the British strains (19 against the $O$ antigens and 11 against the whole organisms), against the typical cholera vibrios 'Inaba' and Ogawa 1077 ( $\mathrm{O}$ and $\mathrm{OH}$ antisera) and against the $\mathrm{O}$ antigens of nine strains representing as many of Taylor \& Ahuja's (1937) Indian vibrio types from water, from carriers, and patients with cholera.

The agglutination technique was similar to that described by Taylor et al. (1937). Suspensions of agar-grown vibrios in $0.25 \%$ formol saline were made of all the British strains, of the true cholera vibrios and of 22 'inagglutinable' Indian strains from various sources.

After preliminary selection by slide agglutination tests, tube agglutination 


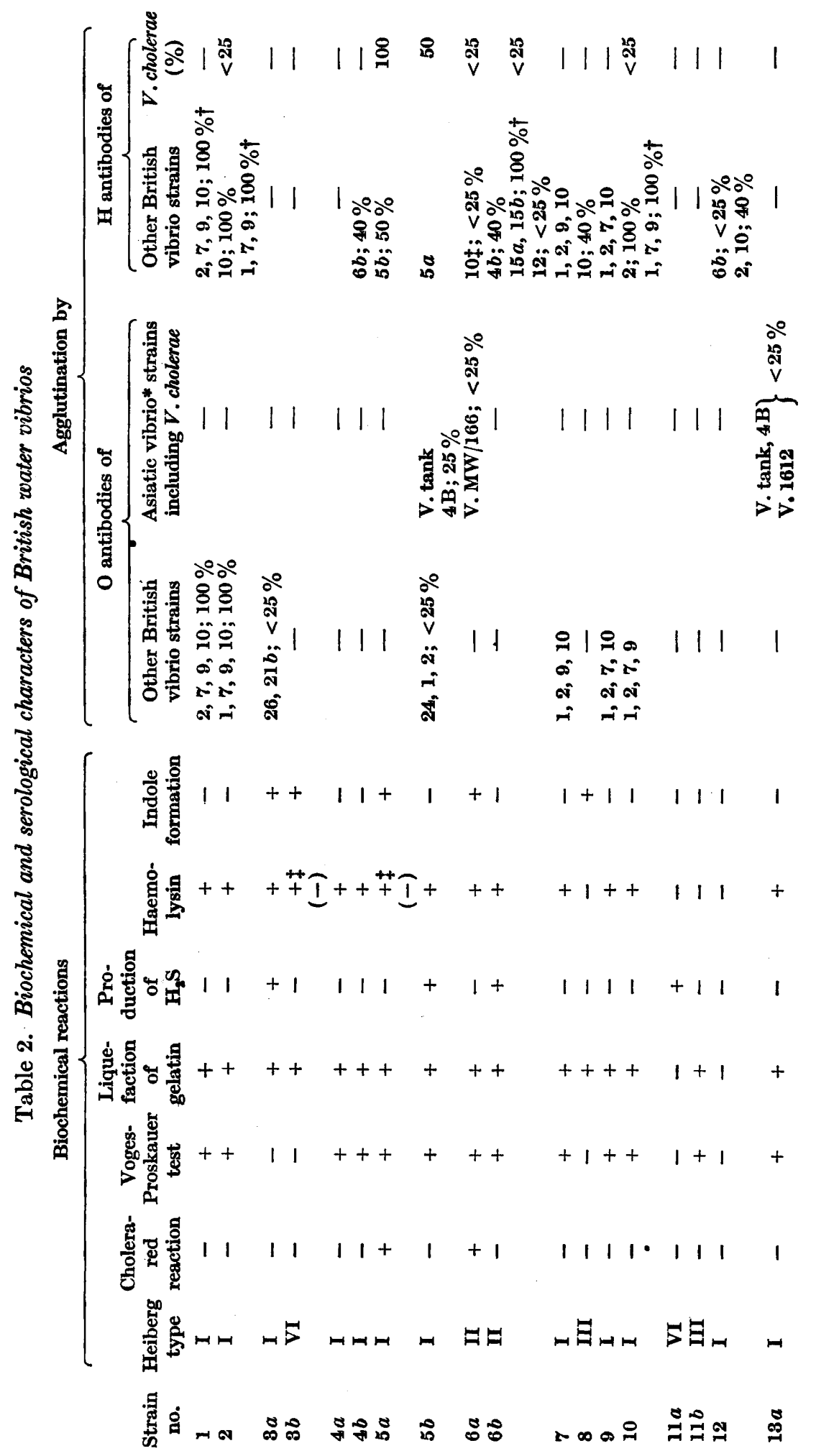




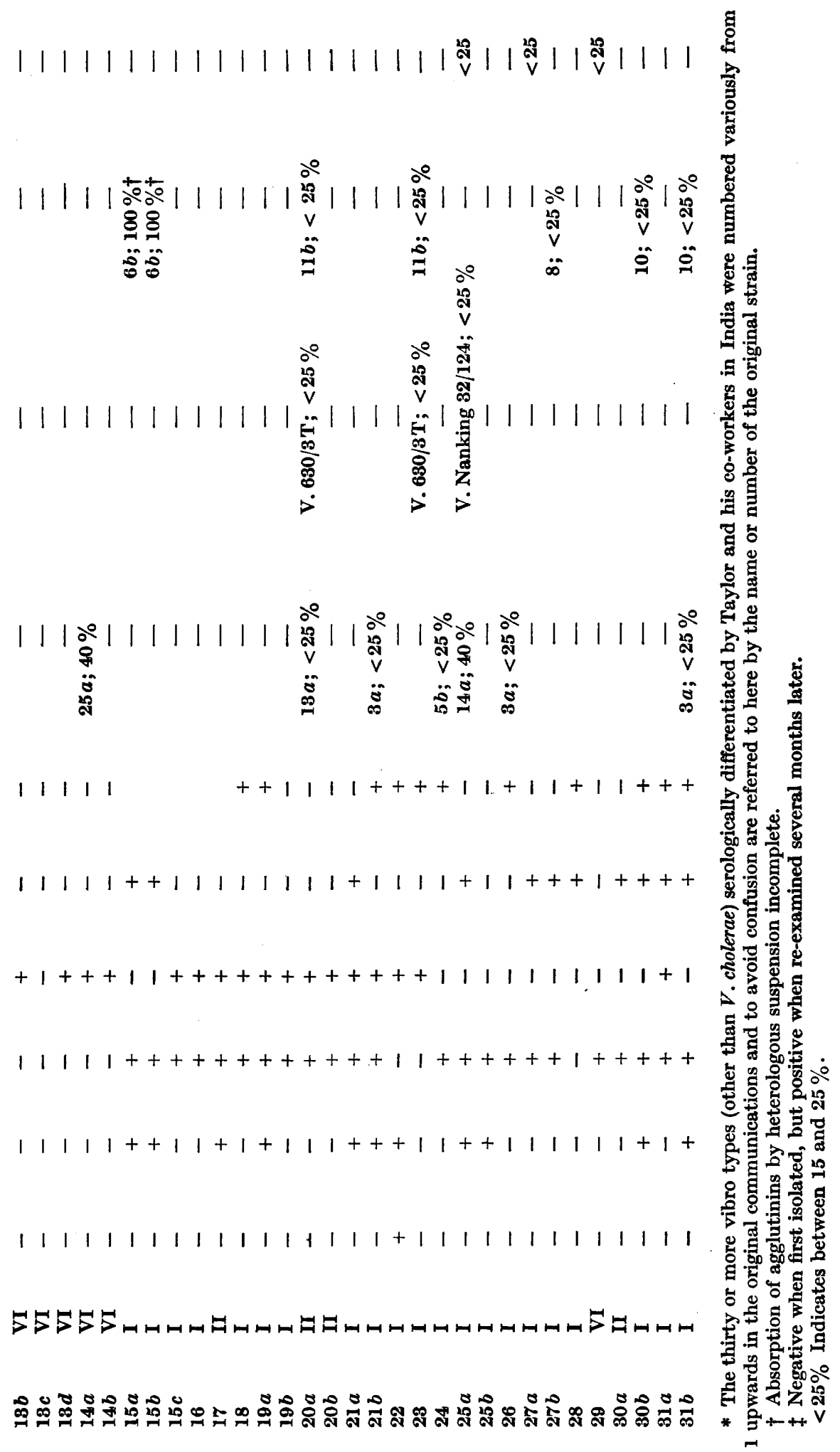


tests were made with all positive reactors, using serum dilutions between $1 / 25$ and $1 / 25,000$. The tubes were incubated in a water-bath at $52^{\circ}$ for $4 \mathrm{hr}$. and readings taken at this term and again after the tubes had stood on the bench overnight.

The results of these agglutination tests are summarized in Table 2. For simplicity cross-reactions amounting to more than $15 \%$ but less than $25 \%$ of the homologous titres of the sera concerned are recorded by the sign $<25 \%$, while those falling below $15 \%$ are entered as negative. It is thought that crossreactions of this order are not sufficiently significant as indices of relationship to warrant their more detailed statement.

As indicated in the table, the British water vibrios proved to be serologically heterogeneous. Of the 50 strains only five $(1,2,7,9$ and 10) were closely related in both their $\mathbf{O}$ and $\mathrm{H}$ antigens, forming a compact group. Two others (14 $a$ and $25 a$ ) showed a measure of similarity limited to the $\mathrm{O}$ antigens; another three or four $(4 a, 6 a, 15 a$ and $15 b)$ showed relationship restricted to the $H$ antigens, and the same was true of the strains $5 a$ and $5 b$ in which the $\mathbf{H}$ antigen appeared to be identical with, or to resemble closely, that of $V$. cholerae. The remaining races were apparently strain specific.

None of the strains reacted appreciably with cholera $\mathrm{O}$ agglutinins and only two to as much as $25 \%$ of the homologous titre with any of the $\mathrm{O}$ antisera prepared against Indian and Far Eastern vibrio types-vibrio 23 with the $O$ antiserum of vibrio 630/3T (a Calcutta 'case' strain, 'strain 9' of Taylor et $a l$.), and vibrio $25 a$ with that of vibrio Nanking 32/124 (also a 'case' strain, Group II, Gardner \& Venkatraman (1935), and 'strain 6' of Taylor et al.).

\section{Phage sensitivity of the strains}

All the strains were tested, as nascent agar-plate cultures, with droplets of concentrated preparations of the Indian cholera phage types $A-I$ and three were found sensitive to certain of these.

$\begin{array}{llllll}\text { Strain } 5 a \text { reacted with phage type B to give 'cloudy lysis' } \\ \text { Strain } 6 a & , & , & \text { B } & \text { total clearing } \\ & " & , & \text { F } & \text { ", } & \text { partial clearing } \\ \text { Strain } 22 & " & , & \text { J } & \text { ", } & \text { partial clearing } \\ & \text { " } & , & \text { B } & \text { ", } & \text { partial clearing } \\ & & \text { J } & \text { " } & \text { partial clearing }\end{array}$

It is interesting to note that these three strains, $5 a, 6 a$ and 22 , were the only members of the series to give a positive cholera-red reaction.

I wish to thank Major-General Sir John Taylor and Mr P. Bruce White for their invaluable encouragement and advice, and Miss Irene Gammon, Miss Edna Schultze and Miss Marie French for their technical assistance.

\section{REFERENCES}

BARritt, M. M. (1936). The intensification of the Voges-Proskauer reaction by the addition of $\alpha$-naphthol. J. Path. Bact. 42, 441.

Bueisch, M. (1893). Ueber einige Fehlerquellen bei Anstellung der Cholera-rothreaktion und ihre Vermeidung. Z. Hyg. Infektkr. 14, 103. 
Gardner, A. D. \& Venkatraman, K. V. (1935). The antigens of the cholera group of vibrios. J. Hyg., Camb., 35, 262.

Goyle, A. N. (1939). Observations on haemolysis by vibrios. Indian J. med. Res. 26, 611 .

Greig, E. D. W. (1916). The serological investigation and classification of choleralike vibrios from water in Calcutta. Indian' J. med. Res. 3, 628.

Houston, A. (1909). The vitality of the cholera vibrio in artificially infected samples of raw Thames, Lea and New River water, with special reference to the question of storage. Res. Rep. metrop. Water Bd. no. 4. Westminster, London: P. S. King.

Houston, A. (1913). Search for certain pathogenic microbes in raw river water and in crude sewage. Res. Rep. metrop. Water Bd. no. 9. Westminster, London: P. S. King.

Taylor, J. \& Ahuja, M. L. (1938). Incidence and characters of vibrios in waters in Northern India. Indian $J$. med. Res. 26, 1.

Taylor, J., Pandit, S. R. \& Read, W. D. B. (1937). A study of the vibrio group and its relation to cholera. Indian J. med. Res. 24, 931.

Taylor, J., Read, W. D. B. \& Pandit, S. R. (1936). Fermentation reactions of vibrios. Indian J. med. Res. 24, 349.

(Received 15 January 1948) 